\title{
Subjective health in spinal cord injury after outpatient healthcare follow-up
}

\author{
M Dunn*,1, L Love ${ }^{1}$ and C Ravesloot ${ }^{2}$ \\ ${ }^{1}$ Spinal Cord Injury Service, Veterans Affairs Palo Alto Health Care System, Palo Alto, California, CA 94304, USA; \\ ${ }^{2}$ Rural Institute on Disabilities, University of Montana, Missoula, Montana, MT 59812, USA
}

\begin{abstract}
Objective: To compare self-reported health, independence, and depression in two samples of people with spinal cord injury (SCI), one which receives regular, comprehensive outpatient health care follow-up and one that does not.

Design: Exploratory study of self-reported secondary conditions in 235 individuals with SCI who received health care follow-up using post hoc quasi-experimental comparisons with a group of 136 people with SCI who had no health care follow-up.

Setting: Outpatients at a Veterans Affairs Health Care System SCI Center.

Main Outcome Measures: The Check Your Health Instrument surveyed three self-report measures: overall health, independence, and depression. The Secondary Conditions Screening Instrument (SCSI) addressed 40 secondary conditions that may have been experienced in the prior year.

Results: Study participants who receive ongoing SCI health care reported higher subjective health, independence, and absence of depression scores compared to those that did not receive regular SCI health care follow-up. Results on the SCSI showed similar secondary conditions in the two groups, but higher frequency and severity in the no follow-up group.

Conclusion: SCI outpatient health care follow-up is associated with higher subjective health, independence, and absence of depression.

Spinal Cord (2000) 38, 84-91
\end{abstract}

Keywords: spinal cord injury; rehabilitation; quality of health care; outcome assessment

\section{Introduction}

Although advances in medical care have increased the survival rate and life expectancy of individuals with spinal cord injury (SCI), secondary conditions and complications may also increase. Can secondary conditions be prevented and reduced in number and/ or severity through ongoing long-term SCI health care follow-up? The necessity of illness prevention and promotion of health maintenance strategies in reducing secondary conditions is well described in the literature. ${ }^{1-6}$ Functional status and outcome measures such as the Functional Independence Measure $(\text { FIM })^{7}$ have been widely used to validate the benefits of acute rehabilitation. A number of reports regarding the necessity of long-term health care follow-up for people with SCI have been published. ${ }^{8-11}$ However, few studies regarding ongoing outcomes of outpatient health maintenance have been reported and those studies did not compare groups with and without SCI health care follow-up. In this era of cost containment and

*Correspondence: M Dunn, Spinal Cord Injury Service, Veterans Affairs Palo Alto Health Care System, 3801 Miranda Avenue, Palo Alto, California, CA 94304, USA accountability it cannot be assumed that outpatient health care follow-up makes a difference. ${ }^{9}$

The First Colloquium on Preventing Secondary Conditions among people with SCI conceptualized secondary conditions as health complications that result in additional functional difficulties superimposed on the original functional losses that resulted from the SCI itself. ${ }^{12}$ The research of Seekins, Clay and Ravesloot ${ }^{13}$ showed that people with disabilities experience an average of fourteen secondary complications per year. Similar findings have been reported by other studies. ${ }^{5,8,11,14}$ The cost of secondary conditions in terms of money and quality of life is tremendous. ${ }^{15,16}$ Secondary conditions may be related to the primary disability (SCI) such as pressure ulcers, pain, or sexual dysfunction; or may be unrelated to the primary disability such as hypertension or diabetes. Aging with SCI as well as the older age of individuals with acute SCI increases the risk of secondary conditions. Furthermore, environmental secondary conditions such as housing, transportation, or accessibility problems as well as psychosocial issues including family strain, personal care problems, 
stress, or depression may impact the individual's quality of life. However, secondary conditions can be prevented or reduced if detected early and managed appropriately through comprehensive ongoing health care.

Despite the presence of secondary conditions, individuals with spinal cord injury may have a strong sense of global subjective health. However, health is difficult to measure. In terms of breadth of definition, health ranges from the absence of diagnosable conditions, on the narrowest end, to 'a state of complete physical, mental, and social well being,' in a broader context. ${ }^{17}$ Fuhrer ${ }^{18}$ addressed the dynamic balance of health between the individual and the environment. Lawton and Lawrence ${ }^{19}$ view the core concept of health as a 'latent construct' that cannot be measured directly but one for which a variety of measurable indicators is available. Defining health is difficult due to its complexities. Health cannot be measured directly but requires consideration of a number of differing facets, which are intercorrelated and overlap between the subjective and objective realms.

Objective measures of health are physiologic or clinical indicators that can be read from an instrument, such as blood pressure or laboratory results; or can be observed, such as tremor or diaphoresis. Clinician global ratings of an individual's health and measures of health behaviors such as physician visits, sick days, or hospitalizations are also objective indicators. Persons with SCI may not be as likely to view their medical problems with the same degree of concern as rehabilitation professionals; therefore, goals and motivation may be different and in conflict. ${ }^{20}$ Subjective health measures are based on a person's self-reported or self-rated global assessment of health rather than a report of specific conditions or symptoms. $^{21}$

There has been a shift away from the traditional medical approach, which concentrated on diagnosis and treatment of disease based on objective measures and toward recognition of the utility of the individual's point of view in monitoring and evaluating health and outcomes. ${ }^{22}$ Krause and his associates ${ }^{23-25}$ found subjective indicators to be better predictors of long-term problems associated with emotional distress, dependency, and health than organic variables. Fuhrer ${ }^{18}$ described positive correlations between self-reported health and life satisfaction. Dijkers $^{26}$ discussed the value of subjective indicators in measuring quality of life. The importance of perceived health in relation to quality of life and rehabilitation outcomes was reported by Whiteneck, Fougeyrollas, and Gerhart ${ }^{27}$ and Krause. ${ }^{28}$

The purpose of this study was to assess subjective health in two samples of people with SCI, one that receives regular, comprehensive outpatient follow-up and one that does not. The hypothesis was that those individuals with SCI who had the opportunity to utilize ongoing SCI health care follow-up after initial rehabilitation would report fewer secondary conditions, increased subjective health and independence, and decreased depression compared to those people with SCI who did not have regular followup.

Due to practical and ethical considerations, this hypothesis can not be directly tested. In order to do so, patients undergoing rehabilitation in one facility would have to be randomly assigned to either a follow-up or no follow-up group and then regularly assessed. Some idea of the effects of outpatient followup can be obtained, however, by examining differences in two groups of individuals who receive or who do not receive follow-up on the basis of availability in the health care system in which they are enrolled. Any differences seen may be due to the system of care as an entirety rather than the presence or absence of followup. Comparing other systems of care, with and without follow-up and with different measures of health may also help triangulate the answer to these questions and will be presented in the discussion.

\section{Method}

\section{Study Design}

The design was an exploratory study of self-reported secondary conditions in individuals with SCI who received ongoing health care follow-up using post hoc quasi-experimental comparisons with a comparison sample that had no SCI health care follow-up. The No Follow-Up group was included as a comparison with the Follow-Up group, but varied two conditions at once, use of health care follow-up and veterans status. Because there was no access to a comparison sample of non-veterans with follow-up, only two groups of subjects were studied. The design was quasi-experimental in that the subjects were not randomly assigned to conditions but were either selfselected or were assigned by virtue of veteran status. That is, non-veterans were ineligible for follow-up treatment so could not be included in the outpatient treatment group. This quasi-experimental design requires inferences to be cautiously made about causal relationships. In spite of these limitations, this design allows some preliminary conclusions to be drawn and currently, there is little data to support ongoing outpatient health care follow-up in SCI.

\section{Formation of the groups and testing procedure}

The Follow-Up group This group was formed by surveying every person with SCI who was seen in the SCI Outpatient Clinic for routine checkups between 4/ 96 and 4/97. During this period of time, 235 people were seen for wellness checkups. When patients checked in for their appointment, they were given the Check Your Health Questionnaire $(\mathrm{CYH})$ by the clinic receptionist and asked to complete it while they were 
waiting to be seen. The clinic receptionist assisted patients who were functionally unable to complete the three questions. Some patients were seen more than once throughout the year, but only the first administration was used for this study. One or two persons from the Follow-Up group were randomly selected each week and asked to complete the Secondary Condition Surveillance Instrument (SCSI). This was administered by the first author who read each item to the patient and marked the patients' response. Fortynine subjects completed the SCSI.

Upon discharge from their initial rehabilitation, patients from the Follow-Up group had been offered and chose to participate in comprehensive, interdisciplinary primary health care follow-up which addressed secondary conditions post-SCI as well as the primary effects of their spinal cord injury. The focus is upon wellness, health promotion, and illness prevention through a continuum of coordinated care. The regional SCI Center, which is part of the Department of Veterans Affairs Health Care System, follows approximately 900 veterans with SCI and has a catchment region covering a large geographic area in the Western United States, including both urban and rural communities. Approximately half of the patient population served by the SCI center live within a $2 \mathrm{~h}$ driving distance from the center and receive care on an outpatient basis through the SCI clinic.

The No Follow-Up Group In order to partially examine the effect of follow-up, data from another dataset was compared to the Follow-Up group. The No Follow-Up group included 136 people with spinal cord injury living in a rural Western state who were either selected from the state's list of handicap parking permit holders or who were served by a Title VII funded center for independent living. The specific sampling procedures for this group have been reported elsewhere. ${ }^{13,29}$

\section{Measures}

The two instruments used to measure secondary conditions were the Secondary Condition Surveillance Instrument (SCSI) and the Check Your Health Questionnaire (CYH). In addition to demographic questions, the SCSI requests the respondents to rate the disability outcome of 40 secondary conditions they may have experienced during the previous year on a scale of 0 to 3 . The 40 secondary conditions are listed along with a brief description of the condition. Labels for the scales are as follows:

zero $=$ the condition has not been a problem one $=$ a mild or infrequent problem (limits activity $1-5 \mathrm{~h}$ per week)

two $=\mathrm{a}$ moderate problem (limits activity $6-10 \mathrm{~h}$ per week)

three $=\mathrm{a}$ significant $/$ chronic problem (limits activity 11 or more h a week).
In addition to the measures of secondary condition severity, single-item measures of perceived Health and Independence were also included in the SCSI questionnaire. Participants were asked to rate their overall Health and Independence during the previous year as excellent, good, fair, or poor. Internal consistency of the SCSI using coefficient alpha has been calculated at $0.88 .{ }^{30}$ The validity of the SCSI is supported by significant correlations between it and other measures of perceived limitation. A significant, negative correlation has been reported elsewhere between the SCSI and the Craig Handicap Assessment and Reporting Technique. ${ }^{31}$ Likewise, a significant positive relationship has been reported between the SCSI and the Centers for Epidemiological Studies of Depression scale. ${ }^{32}$ Hence, the SCSI is a reliable indicator of perceived limitation that is related to variables that are theoretically linked to perceived health. A more detailed description of the SCSI has been published elsewhere. ${ }^{13,33}$

The Check Your Health $(\mathrm{CYH})$ screening instrument is composed of three items drawn from the SCSI. These items are the perceived Health and Independence items and the Depression item. The scale for the Health and Independence items are $3=$ excellent, $2=\operatorname{good}, 1=$ fair, and $0=$ poor. For the Depression item, the scale is $3=$ zero $h$ that depression limited your activity, $2=1-5 \mathrm{~h}, 1=6-10 \mathrm{~h}$, and $0=11$ or more $h$. In order to maintain consistency and the clarity that high scores were 'good', the Depression scale rating was reverse scored for the $\mathrm{CYH}$, so that a high score would reflect better outcome, ie Absence of Depression limitation. Combined, these three items predict $37 \%$ of the reliable variance in total SCSI scores, and hence provide an approximation for total SCSI scores where it is not feasible to administer the entire SCSI scale. Additionally, these three items correctly classify $75 \%$ of those respondents who report substantial limitation due to secondary conditions (ie above the median SCSI score) and $61 \%$ of those reporting less limitation due to secondary conditions. ${ }^{34}$

\section{Data analysis}

Group means were computed for the $\mathrm{CYH}$ scores and SCSI scores. For the SCSI, two additional measures were computed for each of the 40 secondary conditions: Mean Severity for each problem was the Problem Sum divided by the number of endorsers. A Problem Index score was created by multiplying the Mean Severity times the percent of individuals in the sample who endorsed it. Mean Severity reflects the difficulty of a problem for an individual while Problem Index represents the difficulty of a problem for all individuals. For example, spasticity may not affect many people, but may be very severe for those people it affects. The Problem Index reflects frequency and Mean Severity reflects intensity.

Pearson correlations were completed for all continuous variables (Mean Severity, Problem Index, 
length of injury, age, and Health, Independence, and Absence of Depression ratings). An analysis of variance (ANOVA) was used to examine mean length of injury and age of the two groups. A multivariate analysis of variance (MANOVA) was run on the three dependent variables in the $\mathrm{CYH}$ questionnaire (Health, Independence, and Absence of Depression). Group membership (Follow-Up vs No Follow-Up) and subject characteristics (tetraplegic vs paraplegic, race, education, completeness of injury, gender, length of injury, and age) served as the independent variables. All statistical analyses were done using Statview ${ }^{\mathrm{TM}}$.

\section{Subject characteristics}

Demographic characteristics of the groups are shown in Table 1. Chi square tests on the categorical data showed that there were statistically significant differences between the two groups in gender, percent complete injuries, and race; with more women, complete injuries, and Native Americans in the No Follow-Up group and more African-Americans and Latinos in the Follow-Up group. The No Follow-Up group was on the average nine years younger than the Follow-Up group $\left(\mathrm{F}_{2,366}=33.537, P<0.0001\right)$.

Table 1 Subject characteristics

\begin{tabular}{|c|c|c|c|c|}
\hline & \multicolumn{2}{|c|}{ No Follow-Up } & \multicolumn{2}{|c|}{ Follow-Up } \\
\hline Number of subjects & & 136 & \multicolumn{2}{|c|}{235} \\
\hline \multicolumn{5}{|l|}{ Level of injury ${ }^{\mathrm{a}}$} \\
\hline Paraplegic & & $58 \%$ & \multicolumn{2}{|c|}{$52 \%$} \\
\hline Tetraplegic & & 42 & \multicolumn{2}{|c|}{48} \\
\hline \multicolumn{5}{|l|}{ Education $^{\mathrm{a}}$} \\
\hline Grade School & & $3 \%$ & \multicolumn{2}{|c|}{$4 \%$} \\
\hline Some HS & & 15 & \multicolumn{2}{|c|}{2} \\
\hline HS Grad & & 31 & \multicolumn{2}{|c|}{33} \\
\hline Some College & & 32 & \multicolumn{2}{|c|}{50} \\
\hline College Grad & & 10 & \multicolumn{2}{|c|}{4} \\
\hline Post College & & 8 & \multicolumn{2}{|c|}{6} \\
\hline \multicolumn{5}{|l|}{ Injury completeness ${ }^{\mathrm{b}}$} \\
\hline Complete & & $62 \%$ & \multicolumn{2}{|c|}{$46 \%$} \\
\hline Incomplete & & 38 & \multicolumn{2}{|c|}{54} \\
\hline \multicolumn{5}{|l|}{ Gender ${ }^{\mathrm{c}}$} \\
\hline Male & & $66 \%$ & \multicolumn{2}{|c|}{$99 \%$} \\
\hline Female & & 34 & \multicolumn{2}{|c|}{1} \\
\hline \multicolumn{5}{|l|}{ Race $^{\mathrm{d}}$} \\
\hline Caucasian & & $85 \%$ & \multicolumn{2}{|c|}{$75 \%$} \\
\hline African-American & & 4 & \multicolumn{2}{|c|}{13} \\
\hline Asian & & 1 & \multicolumn{2}{|c|}{2} \\
\hline Native American & & 10 & \multicolumn{2}{|c|}{1} \\
\hline \multirow[t]{3}{*}{ Latin } & & 0 & \multicolumn{2}{|c|}{9} \\
\hline & \multicolumn{2}{|c|}{ No Follow-Up } & \multicolumn{2}{|c|}{ Follow-Up } \\
\hline & Mean & $\mathrm{SD}$ & Mean & $\mathrm{SD}$ \\
\hline Length of injury (in years) ${ }^{\mathrm{a}}$ & 18.17 & 11.38 & 19.44 & 13.59 \\
\hline Age (in years) ${ }^{\mathrm{e}}$ & 47.90 & 15.22 & 56.57 & 12.93 \\
\hline Grade achieved $^{\mathrm{a}}$ & 12.93 & 2.88 & 13.64 & 2.28 \\
\hline
\end{tabular}

For the Follow-Up group, half of the subjects had received their injuries while in the military. Forty-one per cent lived with their spouse and/or relatives while 24 per cent lived alone.

\section{Results}

Group effects on Health, Independence and Absence of Depression

A MANOVA showed a statistically significant Wilks' Lambda of $0.948\left(\mathrm{~F}_{3,343}=6.211 ; P=0.0004\right)$ which indicates an overall difference between the two groups on the CYH scales. Subsequent ANOVAs on each of the three variables separately showed a statistically significant difference between the groups on all three variables (Health, Independence, and Absence of Depression). These results are graphically represented in Figure 1.

Post hoc analyses using Fisher's Protected Least Significant Difference Test showed that for all measures, the Follow-Up group reported a statistically significant higher subjective rating than did the No Follow-Up group on Health $(P=0.0068)$, Independence $(P=0.005)$, and Absence of Depression $(P<0.0001)$. Note that on the $\mathrm{CYH}$ a high value on the Absence of Depression item denotes freedom from depression.

\section{Subject characteristics: categorical variables}

For the CYH questionnaire, the effects of the characteristics of the subjects was also examined. In general, there were few effects of subject characteristics. There were no main or interaction effects of the categorical subject characteristics, tetraplegic vs para-

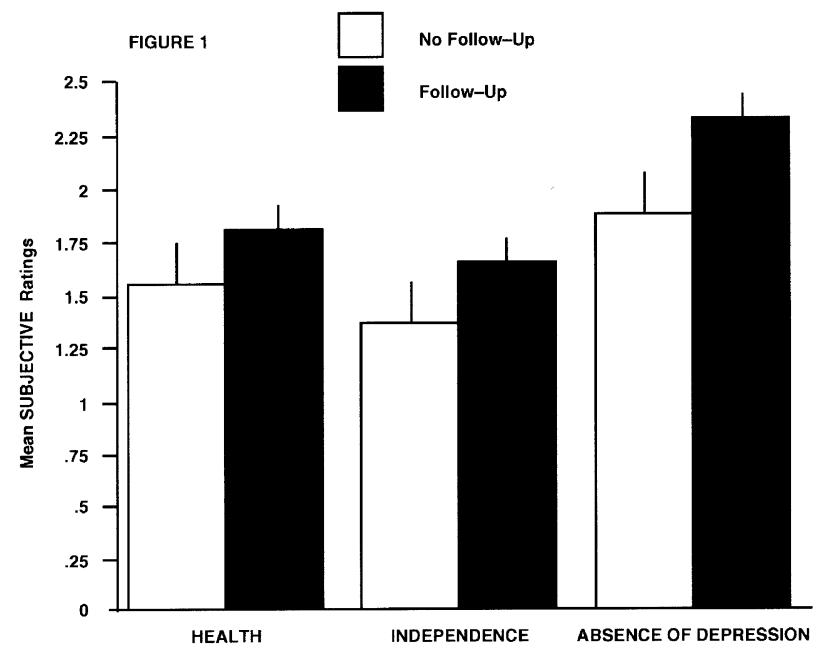

Figure 1 Mean rating for Health, Independence, and Absence of Depression for the two groups. A high score on Absence of Depression indicates less limitation by depression. Error bars indicate one standard error 
plegic, race, complete vs incomplete, or gender, on Health, Independence or Absence of Depression. A MANOVA showed a main effect of Education on Health, Independence and Absence of Depression (Wilks' Lambda $=0.911 ; \mathrm{F}_{15,900}=2.063, \quad P=0.0098$ ). Post hoc analyses using Fisher's Protected Least Significant Difference Test showed, in general that for all three dependent variables, as education increased, the subjects reported greater health and independence and lower depression.

Additional analyses on the Follow-Up group showed that there were no main or interaction effects of the categorical subject characteristics of whether the subjects lived in an urban or rural setting, or whether the subjects had received their injuries while in the military or not.

Subject characteristics: continuous variables

Length of injury was not correlated with Health, Independence, or Absence of Depression for either the Follow-Up or No Follow-Up group, but comparing the two groups on age reveals some interesting but complex relationships. Using age as the covariate in a multivariate analysis of covariance on Health, Independence, and Absence of Depression with Follow-Up as the independent variable showed a significant Age (Wilks' Lambda $=0.916 ; \quad F_{3,340}=10.341, \quad P<0.0001$ ) and Group by Age interaction (Wilks' Lamb$\mathrm{da}=0.966 ; \quad \mathrm{F}_{3,340}=3.974, \quad P=0.0084$. In order to examine this relationship graphically, Health, Independence, and Absence of Depression were plotted as a function of age. This is shown in Figure 2. In this figure, it can be seen that the difference between the Follow-Up and No Follow-Up groups increases with age. The decrease in subjective health ratings with increasing age in the No Follow-Up group is not apparent in the Follow-Up group. Absence of Depression increases with age in the Follow-Up group, but not in the No Follow-Up group. It can also be seen that the variance in the rating is greater in the No Follow-Up group.

Interrelationships among the three dependent variables For the members of the Follow-Up group, Health and Independence were correlated at 0.518, Health and Absence of Depression at 0.303 and Independence and Absence of Depression at 0.311. For the No FollowUp group, these values were $0.718,0.488$, and 0.466 . All these values are statistically significant at $P<0.0001$.

\section{Secondary conditions}

To specify the areas in which the Follow-Up group reported better health, comparisons were made between the No Follow-Up group and the subsample of 49 subjects of the Follow-Up group who were administered the SCSI. There were no significant

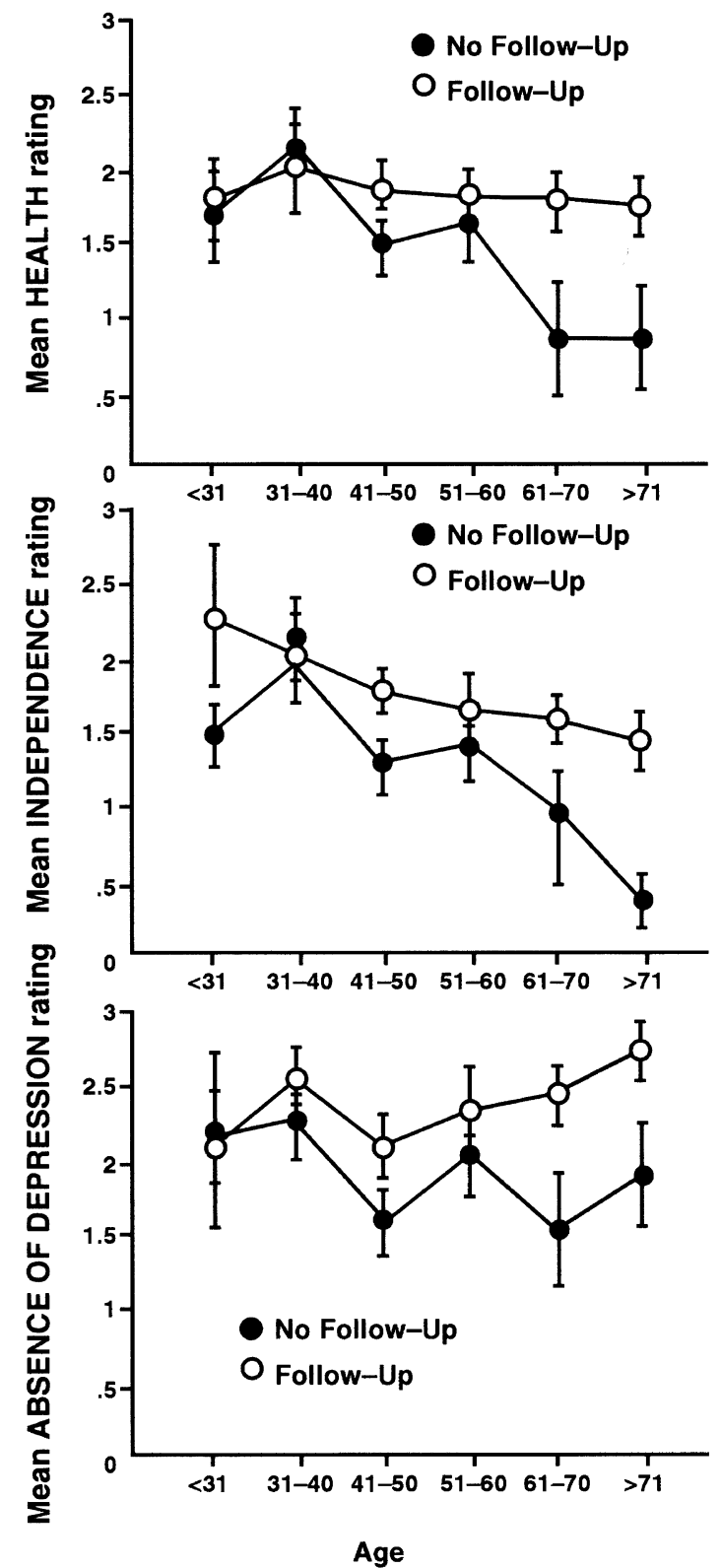

Figure 2 Mean rating for Health (top panel), Independence (middle panel), and Absence of Depression (lower panel) as a function of age for the two groups. A high score on Absence of Depression indicates less limitation by depression. Vertical error bars indicate one standard error

differences among each of the Health, Independence, and Absence of Depression ratings in the 49 subjects who took the $\mathrm{CYH}$ and were then administered the SCSI. The correlations for Health and Independence were 0.921 and 0.812 respectively between the two administrations. The correlations for Absence of Depression rated in the two administrations was 0.549 , less than the others but still statistically significant. The number of secondary conditions endorsed shows a statistically significant difference 
Table 2 Top ten secondary conditions for the Follow-Up and No Follow-Up groups. Sorted by problem index (top panel) and mean severity (bottom panel)

\begin{tabular}{|c|c|c|c|c|c|}
\hline & & $v-U p$ & & $-U p$ & \\
\hline $\begin{array}{l}\text { Mean } \\
\text { severity }\end{array}$ & $\begin{array}{l}\text { Prob } \\
\text { index }\end{array}$ & Top ten item & by problem index & $\begin{array}{c}\text { Mean } \\
\text { severity }\end{array}$ & $\begin{array}{l}\text { Prob } \\
\text { index }\end{array}$ \\
\hline 2.19 & 0.94 & Sexual dysfunction & Access problems & 2.07 & 1.79 \\
\hline 1.83 & 0.86 & Chronic pain & Problems with mobility & 2.25 & 1.69 \\
\hline 1.52 & 0.78 & Fatigue & Bladder dysfunction & 2.02 & 1.45 \\
\hline 1.42 & 0.76 & Joint and muscle pain & Spasticity & 1.99 & 1.45 \\
\hline 1.55 & 0.69 & Spasticity & Chronic pain & 2.13 & 1.44 \\
\hline 1.79 & 0.69 & Physical fitness & Joint and muscle pain & 1.90 & 1.40 \\
\hline 1.65 & 0.67 & Problems with mobility & Physical fitness & 1.98 & 1.37 \\
\hline 1.35 & 0.63 & Access problems & Sexual dysfunction & 2.21 & 1.31 \\
\hline 1.55 & 0.63 & Sleep problems & Urinary tract infection & 1.94 & 1.26 \\
\hline 1.50 & 0.61 & Bowel dysfunction & Sleep problems & 2.01 & 1.26 \\
\hline $\begin{array}{l}\text { Mean } \\
\text { severity }\end{array}$ & $\begin{array}{l}\text { Prob } \\
\text { index }\end{array}$ & Top ten iten & by mean severity & $\begin{array}{c}\text { Mean } \\
\text { severity }\end{array}$ & $\begin{array}{l}\text { Prob } \\
\text { index }\end{array}$ \\
\hline 2.19 & 0.94 & Sexual dysfunction & Problems with mobility & 2.25 & 1.69 \\
\hline 2.00 & 0.08 & Diabetes & Sexual dysfunction & 2.21 & 1.31 \\
\hline 1.90 & 0.39 & Pressure sores & Written comm problems & 2.19 & 0.71 \\
\hline 1.86 & 0.27 & Written comm problems & Arthritis & 2.19 & 0.89 \\
\hline 1.83 & 0.86 & Chronic pain & Chronic pain & 2.13 & 1.44 \\
\hline 1.79 & 0.69 & Physical fitness & Access problems & 2.07 & 1.79 \\
\hline 1.79 & 0.51 & Eating or weight problems & Visual problems & 2.04 & 0.41 \\
\hline 1.67 & 0.10 & Osterporosis & Bladder dysfunction & 2.02 & 1.45 \\
\hline 1.65 & 0.67 & Problems with mobility & Depression & 2.01 & 1.15 \\
\hline 1.64 & 0.47 & Contractures & Sleep problems & 2.01 & 1.26 \\
\hline
\end{tabular}

Bold items are common to both groups

$\left(\mathrm{F}_{1,183}=41.478, P<0.0001\right)$ with the Follow-Up group endorsing almost half the number of secondary conditions as the No Follow-Up group (8.8 vs 16). Table 2 shows the top ten secondary conditions in terms of Problem Index (top panel) and Mean Severity (bottom panel).

In each panel, secondary conditions appearing in both groups are in bold. For example, sexual dysfunction, written communication problems, chronic pain, and mobility issues are problems for both groups in terms of Mean Severity. Note that there is considerable overlap in both groups for the Problem Index, a measure of how frequently the problem occurs, but less overlap in the items ranked by Mean Severity, a measure of difficulty for the individual. One may conclude from this that the secondary conditions are the same in the Follow-Up and No Follow-Up groups, but the severity and frequency is less in the Follow-Up group.

\section{Discussion}

The current study found that individuals with SCI who had no opportunity for follow-up health care reported lower Health and Independence, and more Depression than a group of people who received their follow-up in a regional SCI Center. Furthermore, an examination of the types of secondary conditions that people report following SCI reveals that the types of secondary conditions are similar, but the frequency and severity is less in people that receive follow-up. Certain methodological limitations of the current study, however, do limit its interpretation and generalizability.

The difference between the two groups might be attributed to the presence or absence of follow-up, veterans status, rural/urban living situation, or other factors of which we are unaware. The absence of a non-veteran group with follow-up and the post hoc analysis of this study limit the ability to infer that the active difference in the two groups is the presence or absence of follow-up. The two groups were demographically similar, but it still is not known if veterans status, presence of follow-up, or something else caused the main effect. One point does argue in favor of the follow-up interpretation, however. Survey data from institutions that treat non-veterans and do regular follow-up shows similar results to the present study. Data from Rintala et $a l^{5}$ demonstrated that her sample of non-veterans reported similar patterns and severity of health problems as did the veterans who receive follow-up. She has confirmed in a personal communication that most of the subjects in her study were in regular follow-up programs. Similarly, Britell ${ }^{8}$ has reported on the health issues of veterans in a VA SCI Center that provides ongoing follow-up. Comparison of that data with the current study showed a similar rank order of the top rated secondary conditions (Spearman rank order correlation $=0.625 ; P<0.05$ ). 
The advantage of the current study is that the same measuring instruments, the CYH and SCSI, were used to assess the two groups. Follow-up is thought to be the active component but there is insufficient data to confirm that position at the present time.

From a methodological point of view, it would have been useful to have had a non-veteran follow-up group, but there was no direct access to such a group at the time and withholding treatment follow-up from a randomly selected veteran group would be ethically and legally inappropriate. However, since comprehensive follow-up has been shown to be effective in other populations (see the studies of Rintala $e t a l^{5}$ and Britell ${ }^{8}$ ), support for the generalizability of the current results is increased.

Despite these methodological limitations, certain findings are of interest and will be discussed. It is not surprising that the No Follow-Up and Follow-Up groups identified the same secondary conditions as problems, in that those with SCI are at risk for similar secondary conditions. However, severity was greater in the No Follow-Up group. Anson and Shepherd ${ }^{35}$ found that individuals with SCI who were treated at the regional SCI center had significantly fewer medical problems than those who were treated at an outreach clinic. A similar superiority of specialized SCI centers over general hospital care has been demonstrated in inpatient rehabilitation. ${ }^{36}$

The differential relationship between age and health and age and depression in the two groups was unexpected. It would be tempting to note that follow-up may protect people with SCI from the effects of aging, since subjective health did not decrease and absence of depression increased in this group. However, the methodological limitations previously discussed as well as the small numbers of subjects in each of the age groups precludes such a premature conclusion. More research is needed.

\section{Conclusion}

A specialized, comprehensive, outpatient program offering ongoing health care for individuals with spinal cord injury is associated with increased subjective health and independence and less depression than those who do not receive this follow-up. Additionally, the severity and frequency of secondary conditions is less for individuals who receive outpatient follow-up at a spinal cord injury center. In spite of the methodological limitations inherent in comparing two healthcare delivery systems, such as incomparability of subjects and the impossibility of a veteran with no Follow-Up group, this study supports the concept that secondary conditions may be reduced through provision of long-term outpatient health care utilizing a health promotion focus for individuals with spinal cord injury.

\section{Acknowledgements}

Part of this material was presented at the annual educational conference of the American Association of Spinal Cord Injury Nurses, Las Vegas, NV, 1997.

\section{References}

1 Buck EL et al. Utilization of health care services by persons with spinal cord injury living in the community. American Congress of Rehabilitation Medicine 1993.

2 Lanig IS et al. A Practical Guide to Health Promotion after Spinal Cord Injury. Aspen; Gaithersburg, Maryland, 1996.

3 Canupp KC, Waites KB, DeVivo MJ, Richards JS. Predicting compliance with annual follow-up evaluations in persons with spinal cord injury. Spinal Cord 1997; 35: 314-319.

4 DeJong G. Primary care for persons with disabilities: An overview of the problem. American Journal of Physical Medicine and Rehabilitation 1997; 76 (Suppl.): S2-S8.

5 Prevalence of health problems experienced by a communitybased sample of adults with spinal cord injury. ACRM 1997; Boston.

6 Post MWM, et al. Predictors of health status and life satisfaction in spinal cord injury. Archives of Physical Medicine and Rehabilitation 1998; 79: 395-401.

7 Guide for the Uniform Data set for Medical Rehabilitation (Adult FIM), Version 5.0. Buffalo (NY). State University of New York at Buffalo, Buffalo, NY 1996.

8 Britell CW, Umlauf R, Loehr JT, DeLisa JA. Survey of health issues in spinal cord injured outpatients. Archives of Physical Medicine and Rehabilitation 1986; 67: 654 (abs.).

9 Fiedler KJ. Spinal Cord Injured Patients' annual evaluation: Outcome and efficacy. Neurology 1995; 45 (suppl 4): A328 (abs.).

10 Johnson LJ, Bosshart HT, Sridharan V. An outpatient model for comprehensive SCI annual evaluations. SCI Psychosocial Process 1997; 10: 154 (abs.).

11 Ernst JL, Thomas LM, Hahnstadt WA, Piskule A. The selfidentified long-term care needs of persons with SCI. SCI Psychosocial Process 1998; 10: $127-132$.

12 Fuhrer MF. Setting the conceptual landscape. In: Graitcer PL, Maynard FM, (eds). Proceedings from the First Colloquium on Preventing Secondary Disabilities among People with Spinal Cord Injuries. February 27-28 1990, Department of Health and Human Services, Centers for Disease Control and Prevention, Atlanta, GA, 1991, pp. 37-46.

13 Seekins T, Clay J, Ravesloot C. A descriptive study of secondary conditions reported by a population of adults with physical disabilities served by three independent living centers in a rural state. Journal of Rehabilitation 1994; $47-51$.

14 Britell M, Umlauf. Two-year survey of health issues in spinal cord injured outpatients. Archives of Physical Medicine and Rehabilitation 1988; 69: 765 (abs.).

15 Stover S, Fine P. Spinal cord injury: Facts and figures. Birmingham: The University of Alabama at Birmingham, 1986.

16 DeVivo MJ, Whiteneck Jr GGEDC. The Economic Impact of Spinal Cord Injury. In: Stover SL, DeLisa JA, Whiteneck GG (eds). Spinal Cord Injury: Clinical outcomes from the model systems. Gaithersburg, MD: Aspen, 1995; pp. 234-271.

17 The constitution of the W.H.O. Geneva: World Health Organization, 1947.

18 Fuhrer MJ et al. Relationship of life satisfaction to impairment, disability, and handicap among persons with SCI living in the community. Archives of Physical Medicine and Rehabilitation 1992; 73: $552-557$.

19 Lawton MP, Lawrence RH. Assessing Health. In: Lawton MP, Teresin JA (eds). Annual Review of Gerontology and Geriatrics. Springer: New York, 1994; pp. 23-56.

20 Krause JS, Crewe N. Long-term prediction of self-reported problems following Spinal Cord Injury. Paraplegia 1990; 28: $186-202$.

21 Hoenig $\mathrm{H}$ et al. The reliability of a self-reported measure of disease, impairment, and function in persons with spinal cord dysfunction. Archives of Physical Medicine and Rehabilitation 1998; 79: $378-387$.

22 Jenkinson C. Evaluating the efficacy of medical treatment possibilities and limitations. Social Science Medicine 1995; 41: $1395-1401$. 
23 Krause JS, Crewe NM. Prediction of long-term survival of persons with spinal cord injury: An 11-year prospective study. Rehabilitation Psychology 1987; 32: 205-213.

24 Krause JS. Survival following spinal cord injury: A 15-year prospective study. Rehabilitation Psychology 1991; 36: 89-98.

25 Krause JS, Sternberg M, Loffes S, Maides J. Mortality after spinal cord injury: An 11-Year prospective study. Arch Phys Med Rehabil 1997; 78: $815-821$.

26 Dijkers M. Measuring quality of life. In: Fuhrer MJ (ed). Assessing Medical Rehabilitation Practices: The Promise of Outcomes Research. Paul H. Brooks Publishing: Baltimore, $1997 ; 153-179$

27 Whiteneck GG, Fougeyrollas P, Gerhart KA. Elaborating the model of disablement. In: Fuhrer MJ (ed). Assessing Medical Rehabilitation Practices: The Promise of Outcomes Research. Paul H. Brookes Publishing: Baltimore, 1997; pp. 91-102.

28 Krause JS. Intercorrelations between secondary conditions and life adjustment in people with spinal cord injury. $S C I$ Psychosocial Process 1998; 11: 3-7.

29 Revesloot C, Seekins T. A structural analysis of secondary conditions experienced by people with physical disabilities. Rehabilitation Psychology 1997; 42: 3-16.

30 Ravesloot C, Seekins T, Young QR. Health Promotion for people with chronic illness and physical disabilities: The connection between health psychology and disability prevention. Health Psychology: Special Edition of Clinical Psychology and Psychotherapy-An International Journal of Theory and Practice 1998; 5, 76-85.
31 Whiteneck GG et al. Quantifying handicap: A new measure of long-term rehabilitation outcomes. Archives of Physical Medicine and Rehabilitation 1992; 73: 519-526.

32 Radloff LS. The CES-D Scale: A self-report depression scale for research in the general population. Applied Psychological Measurement 1977; 1: 385-401.

33 Seekins $\mathrm{T}$ et al. Secondary Disability Prevention: Involving consumers in the development of a public health surveillance instrument. Journal of Disability Policy Studies 1990; 1: 21 - 36.

34 Seekins T, Norris K, Young Q, Ravesloot C. Check Your Health: Consumer Screening Manual and Forms. University of Montana: Missoula, MT, 1997.

35 Anson C, Shepherd C. Incidence of secondary complications in spinal cord injury. International Journal of Rehabilitation Research 1996; 19: $55-66$.

36 Heinemann A et al. Functional outcome following SCI: a comparison of specialized spinal cord injury center vs. general hospital short-term care. Arch Neurol 1989; 46: 1098 - 1102. 